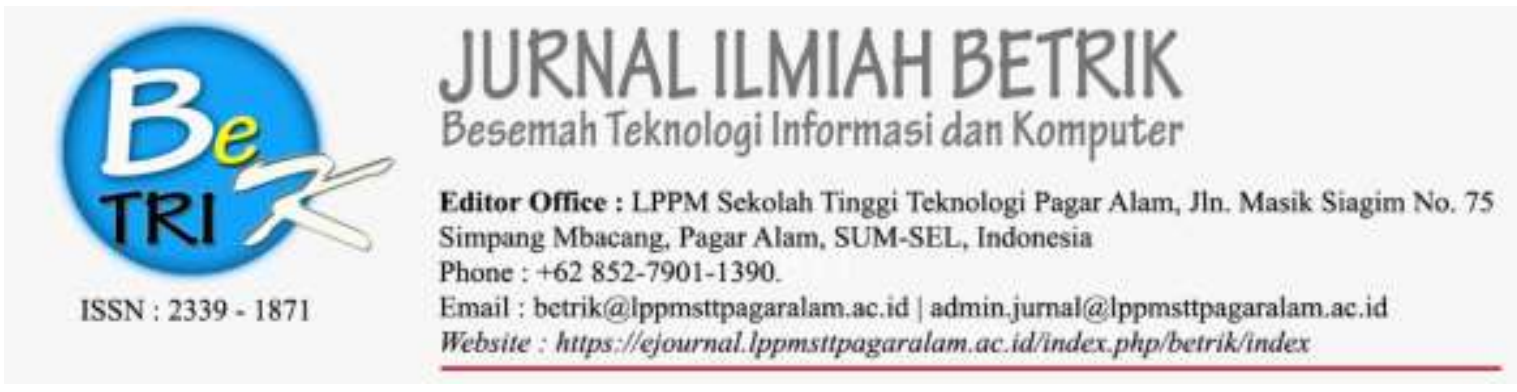

\title{
PERANGKAT LUNAK BANTU PENERIMAAN SISWA BARU PADA SD METHODIST-5 PAGAR ALAM
}

\author{
Desi Puspita \\ Dosen Sekolah Tinggi Teknologi Pagar Alam ${ }^{12}$ \\ Jalan Masik Siagim No.75 Simpang Mbancang Kec.Dempo Tengah Kota Pagar Alam \\ Sur-el: desiofira1@gmail.com
}

\begin{abstract}
Software is a computer program associated with software documentation such as need documentation, design model, and user manual or a computer program without associated documentation. Software built by engineering is not manufactured by manufacture or manufacturer. The purpose of the development of software aids is to assist data collection in the process of admission of new students in SD Methodist-5 Pagar Alam. The process of data collection applied in SD Methodist-5 Pagar Alam is by using conventional method, that is by recording data process of new student acceptance which still using ledger, so that in process of data searching and report making can take a long time. Software development model used in this research is waterfall model that includes: System Engineering, Requirement analysis, Design, Coding, Testing and Maintenance.
\end{abstract}

Keywords: Software aids, data collection process, waterfall model

\begin{abstract}
Abstrak :Perangkat lunak (software) adalah program komputer yang terasosiasi dengan dokumentsi perangkat lunak seperti dokumentasi kebutuhan, model desain, dan cara penggunaan (user manual) atau sebuah program komputer tanpa terasosiasi dengan dokumentasinya. Perangkat lunak dibangun dengan rekayasa bukan diproduksi secara manufaktur atau pabrikan. Tujuan dibangunnya perangkat lunak bantu adalah untuk membantu pendataan dalam proses penerimaan siswa baru di SD Methodist-5 Pagar Alam. Proses pendataan yang diterapkan di SD Methodist-5 Pagar Alam yaitu dengan menggunakan metode konvensional, yaitu dengan proses pencatatan data penerimaan siswa baru yang masih menggunakan buku besar, sehingga dalam proses pencariaan data dan pembuatan laporan dapat memerlukan waktu yang cukup lama. Model pengembangan perangkat lunak yang digunakan dalam penelitian ini adalah model waterfall yaitu meliputi: System Engineering, Requirement analysis, Design, Coding, Testing dan Maintenance.
\end{abstract}

Kata Kunci :Perangkat lunak bantu, proses pendataan, model waterfall

\section{PENDAHULUAN}

Perkembangan teknologi dalam era globalisasi saat ini sudah sangat pesat dan semakin canggih dalam kehidupan sehari-hari.
Alter menjelaskan teknologi informasi merupakan mencakup perangkat keras dan perangkat lunak untuk melaksanakan satu atau sejumlah tugas pemrosesan data seperti 
menangkap, mentransmisikan, menyimpan, mengambil, memanipulasi, atau menampilkan data(Kadir, 2003, pp. 13-15).

SD Methodist-5 Pagar Alam merupakan lembaga pendidikan yang berada dalam naungan badan atau yayasan pendidikan gereja methodist Indonesia dalam wilayah II.Pada SD Methodist-5 Pagar Alam setiap tahun ajaran baru akan dibuka penerimaan siswa baru bagi calon siswa yang akan mendaftar menjadi siswa baru di SD Methodist-5 Pagar Alam.

Dalam penelitian Wahyu hidayat (2013) dengan judul "Pembangunan Sistem Informasi Pendaftaran Siswa Baru SMP Negeri 2 Sudimorto Pacitan", dengan hasil penelitian penerimaan siswa baru merupakan salah satu proses yang ada di instansi pendidikan. Pencatatan data siswa siswa baru pada SMP N 2 Sudimoro Pacitan masih menggunakan metode konvensional, yakni setiap pencatatan data siswa baru disimpan dengan menggunakan buku besar, yang sering kali mempersulit dalam proses pencarian data, hilangnya dokumen serta membutuhkan waktu dalam proses pencarian data, hilangnya dokumen serta membutuhkan waktu yang lama dalam pembuatan laporan. Maka dalam penelitian ini akan dibuat sebuah aplikasi pencatatan data siswa baru agar mempermudah proses pengolahan data.

Dalam penelitian Santoso (2015) dengan judul "Sistem Informasi Pendaftaran Siswa Baru SMK di Ponorogo Tulak", dengan penelitian pada SMK Diponorogo Tulakan dalam pengolahan pendaftaran siswa baru masih menggunakan metode pencatatan manual.Sistem informasi ini bertujuan untuk memudahkan dalam adminitrasi pendaftaran siswa baru yang membantu bagi panitia penerimaan siswa baru pada instansi tersebut.Metode yang digunakan adalah keperpustakan, observasi analisis perancangan dan pengujian program.serta menggunakan program Visual Basic 6.0 dan Microsof Access 2007.

Dalam penelitian Nur Heri Cahyana dkk (2013) dengan judul "Penerimaan Siswa Baru Berbasis WEB (SMK Negeri 3 Yogyajarta)", dengan penelitian penerimaan siswa baru berbasis web di harapkan dapat memudahkan para calon pendaftar untuk melakukan pendaftaran dan mencari informasi tentang sekolah yang dituju. Selain itu dengan adanya penerimaan siswa baru berbasis web hasil pendaftaran dapat dilihat lebih cepat. Aplikasi untuk web pendaftaran siswa baru secara online menggunakan pemrograman $p h p$ dan xampp sebagai web server yang didalamnya memuat apache. Aplikasi ini ditujukan agar dapat proses yang meliputi nilai akhir siswa baru dapat ditingkatkan dan lebih efisien pengerjaannya.

Penerimaan siswa baru merupakan salah satu proses yang ada di instansi pendidikan untuk menyeleksi calon siswa baru. Teknologi yang semakin berkembang dapat membantu dalam pengolahan data yang sebelumnya menggunakan buku besar menjadi komputerisasi dengan menggunakan perangkat lunak bantu. Sehingga sistem tersebut terkesan tidak efektif dan efisien jika dilakukan dalam jangka panjang.

Berdasarkan informasi yang telah dapatkan dari hasil observasi dan wawancara 
dengan kepala sekolah serta staf di SD Methodist-5 Pagar Alam yang menyatakan bahwa proses pencatatan dan pengolahan data penerimaan siswa baru yang telah dilaksanakan sampai saat ini masih menggunakan metode konvensional, yakni dimana metode ini dalam proses penyimpanan dengan menggunakan buku besar. Sehingga hasil yang selama ini berjalan belum maksimal masih banyak kekurangan dalam pengolahan data maupun dalam proses pencariaan data. Adapun tahapan pendaftaran untuk calon siswa baru pada SD Methodist-5 Pagar Alam saat ini yaitu wali calon siswa harus meminta formulir kepada petugas penerimaan siswa baru. Pada formulir tersebut terdapat syarat-syarat untuk mendaftar yaitu fotocopy akta kelahiran (2 Lembar), fotocopy kartu keluarga (2 Lembar), map folio warna biru (2 Lembar), pas foto hitam putih dan berwarna $3 \times 4$ (4 Lembar) dan biaya pendaftaran $\mathrm{Rp} 75.000,-$. Setelah wali calon siswa melengkapi persyaratan dan formulir yang sudah di isi diserahkan kepada petugas penerimaan siswa baru.

Dari permasalahan yang telah dijelaskan diatas proses pendataan pada penerimaan siswa baru belum menggunakan sistem yang berbasis komputerisasi sehingga dalam proses pengolahan data penerimaan siswa baru mengalami suatu permasalahan dalam melakukan pengarsipan data penerimaan siswa baru dan data pelayanan pada saat penerimaan siswa baru. Dengan adanya penerimaan siswa baru yang berbasis komputerisasi diharapkan proses dalam pengolahan data penerimaan siswa baru akan menjadi lebih baik.
Tujuandari penelitian yaitu untuk membuat dan menghasilkan perangkat lunak bantu penerimaan siswa baru pada SD Methodist-5 Pagar Alam. Sehingga dapat membantu dalam proses pendataan dalam penerimaan calon siswa baru.

\section{METODOLOGI PENELTIAN}

\subsection{Waktu dan Tempat Penelitian}

Lokasi penelitian beralamat di Jalan Kampung Melati No. 723 A dan dilaksanakann pada bulan Oktober 2016 sampai bulan Juni 2017.

\subsection{Metode Pengumpulan Data}

Dalam pengumpulan data ini ada metode-metode yang digunakan untuk mencari informasi tentang objek yang diteliti (M.Shalahuddin R. A., 2014, pp. 28-31), yaitu:

\section{Metode Observasi}

Metode Observasi merupakan pengamatan dan menganalisis yang telah di lihat langsung terhadap objek yang diteliti yang telah menjadi sumber masalah, seperti melihat bagaimana proses dan pendataan penerimaan siswa baru yang selama ini dilaksanakan di SD Methodist5 Pagar Alam.

2. Metode Wawancara

Metode Wawancara merupakan proses tanya jawab penelitian secara langsung melalui narasumber, yaitu dengan bertanya langsung kepada kelapa sekolah dan petugas penerimaan siswa baru yang berada pada SD Methodist-5 Pagar Alam tentang bagaimana metode pendataan penerimaan siswa baru di SD Methodist-5 Pagar Alam.

3. Metode Kepustakaan

Metode kepustakaan merupakan proses mengumpulkan data-data yang dibutuhkan, 
dengan cara pengambilan data dari bukubuku dan sumber-sumber pustaka lainnya yang ada kaitannya dengan data penerimaan siswa baru.

\section{Metode Dokumentasi}

Metode dokumentasi merupakan metodepengumpulan data yang dilakukan dengan cara menggunakan data-data yang telah diperoleh dari sekolah seperti data siswa maupun arsip-arsip yang berkaitan dengan pembuatan perangkat lunak bantu penerimaan siswa baru.

\subsection{Metode Pengembangan Sistem}

Model SDLC air terjun (waterfall) sering juga disebut model sekunsial linier (sequential linear) atau alur hidup klasik (classic life cycle).Model air terjun menyediakan pendekatan alur hidup perangkat lunak secara sekuensial atau terurut dimulai dari system engeneering, requirements analysis, design, coding, testing dan maintenance.(M.Shallahudin, 2014, pp. 2831)Berikut adalah gambaran model air terjun (waterfall) :

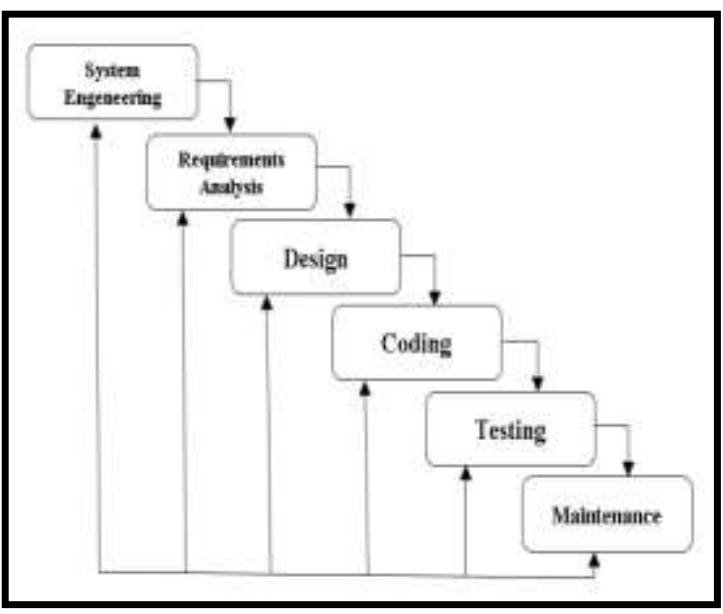

Gambar 1. Model Waterfall

\subsection{Perangkat Lunak}

Perangkat lunak (software) adalah program komputer yang terasosiasi dengan dokumentsi perangkat lunak seperti dokumentasi kebutuhan, model desain, dan cara penggunaan (user manual) atau sebuah program komputer tanpa terasosiasi dengan dokumentasinya. Perangkat lunak dibangun dengan rekayasa bukan diproduksi secara maufaktur atau pabrikan.(M.Shallahudin R. A., 2014, p. 2) Perangkat lunak bantu adalah program komputer dan dokumentasi yang berhubungan.(Sommerville, software engineering, 2003, pp. 5-6) Maka penulis dapat menyimpulkan bahwa perangkat lunak bantu adalah suatu proses yang tidak hanya mencangkup program, tetapi juga dokumentasi dan konfigursi data yang berelasi yang dibutuhkan untuk membuat agar program beroperasi dengan benar.

\subsection{PHP(Hypertext Preprocessor)}

PHP (Hypertext Preprocessor) adalah bahasa server-side scripting yang menyatu dengan HTML untuk membuat halaman web yang dinamis. Karena PHP merupakan serverside scripting maka sintaks dan perintahperintah PHP akan dieksekusi di server kemudian hasilnya dikirimkan ke browser dalam format HTML. Dengan demikian kode program yang ditulis dalam PHP tidak akan terlihat oleh user sehingga keamanan halaman web lebih terjamin. PHP termasuk dalam Open Source Product, sehingga source code PHP dapat diubah dan didistribusikan secara bebas.PHP dirancang untuk membentuk halaman web yang dinamis, yaitu halaman web yang dapat membentuk suatu tampilan 
berdasarkan permintaan terkini, seperti menampilakan isi basis data ke halaman web.(Arief M. , 2011, p. 43)

\subsection{MySQL}

MySQL merupakan database yang pertama kali didukung oleh bahasa pemrograman script untuk internet $(P H P$ dan Perl). MySQL lebih sering digunakan untuk membangun aplikasi berbasis web, umumnya pengembangan aplikasinya menggunakan bahasa pemrograman script PHP. MySQL termasuk RDBMS (Relational Database Management System. Itulah sebabnya istilah tabel, baris, dan kolom digunakan pada MySQL. Pada MySQL, sebuah database mengandung satu atau sejumlah tabel. Tabel terdiri atas sejumlah kolom dan baris, dimana setiap kolom berisi sekumpulan data yang memiliki tipe yang sejenis, dan baris merupakan sekumpulan data yang saling berkaitan dan membentuk informasi. Kolom biasanya juga disebut sebagai field dan informasi yang tersimpan dalam setiap baris disebut record.(Arief M. , 2011, p. 43)

\subsection{Dreammeaver}

Dreamweaver merupakan software utama yang digunakan oleh WebDesainer maupun Web Programmer dalam mengembangkan suatu situs web.Hal ini disebabkan ruang kerja, fasilitas dan kemampuan dreamweaver yang mampu meningkatkan produktivitas dan efektivitas dalam desain maupun membangun suatu situs web.(T A. H., 2008, p. 3)

\subsection{Web}

Web merupakan salah satu aplikasi yang berisikan dokumen-dokumen multimedia (teks, gambar, suara, animasi, video) didalamnya ysng menggunsksn protocol HTTP (hypertext transfer protocol) dan untuk mengaksesnya menggunakan perangkat lunak yang disebut browser. Beberapa jenis browser yang populer saat ini di antaranya: internet Explorer yang diproduksi oleh Microsoft, Mozilla Firefox, Opera, dan Safari yang di peroduksi oleh Apple. (Arief M. , 2011, p. 43)

\subsection{Basis Data (Database)}

Basis data (database) merupakan suatu pengorganisasi sekumpulan data yang saling terkait sehingga memudahkan aktivitas untuk memperoleh informasi. Basis data dimaksudkan untuk mengatasi masalah pada sistem yang memakai pendekatan berbasis berkas. Untuk mengolah basis data diperlukan perangkat lunak yang disebut DBMS (Database Management System ). (Abdul, 2003)

\subsection{0. Хampp}

Xampp adalah sebuah softwareweb server apache yang didalamnya sudah tersedia database server MySQL dan dapat mendukung pemrograman PHP.XAMPP merupakan software yang mudah digunakan, gratis dan mendukung instalasi di Linux dan Windows.Keuntungan lainnya adalah cuma menginstal satu kali sudah tersedia Apache Web Server, MySQL Database Server, PHP Support dan beberapa module lainnya.(Zuliarso, 2012, pp. 124-132)

\subsection{Teori Perancangan UML (Unified Modeling Language) \\ UML (Unified Modeling Language)} adalah salah satu standar bahasa yang banyak digunakan di dunia industry untuk 
mendefinisikan requirement, membuat analisis dan desain, serta menggambarkan arsitektur dalam pemrograman berorientasi objek.(M.Shalahuddin R. A., 2014, p. 133)UML (Unified Modeling Language) muncul karena adanya kebutuhan pemodelan visual untuk menspesifikasikan, menggambarkan, membangun, dan dokumentasi dari system perangkat lunak. Ada 4 notasi UML (Unified Modeling Language)yaitu :

\section{Class Diagram}

Diagram kelas atau class diagram menggambarkan struktur sistem dari segi pendefinisian kelas-kelas yang akan dibuat untuk membangun sistem.kelas memiliki apa yang disebut atribut dan metode atau operasi. (M.Shalahuddin R. A., 2014, p. 133)

\section{Use Case Diagram}

Use case atau diagram use case merupakan pemodelan untuk kelakuan (behavior) sistem informasi yang dibuat. Use case mendeskripsikan sebuah interaksi antara satu atau lebih actor dengansistem informasi yang akan dibuat. Secara kasar, Use case digunakan untuk mengetahui fungsi apa saja yang ada didalam sebuah sistem informasi dan siapa saja yang berhak menggunakan fungsi-fungsi itu. (M.Salahuddin R. A., 2014, p. 155)

\section{Activity Diagram}

Diagram aktivitas atau activity diagram menggambarkan workflow (aliran kerja) atau aktivitas dari sebuah system atau proses bisnis atau menu yang ada pada perangkat lunak. Yang perlu diperhatikan disini adalah bahwa diagram menggambarkan aktivitas system bukan apa yang dilakukan aktor, jadi ktivitas yang dapat dilakukan oleh sistem.(M.Salahuddin R. A., 2014, p. 161)

\section{Sequence Diagram}

Diagram sekuen menggambarkan kelakuan objek pada use case dengan mendeskripsikan waktu hidup objek dan message yang dikirimkan dan diterima antar objek. Membuat diagram sekuen juga dibutuhkan untukuntuk melihat scenario yang ada pada use case.(M.Shalahuddin R. A., 2014, p. 165)

\subsection{Rancangan yang diusulkan}

\subsubsection{Sistem yang Berjalan}

Sistem pendataan penerimaan siswa baru yang berjalan saat ini di SD Methodist-5 Pagar Alam yaitu dengan menggunakan buku, yaitu dimana calon wali siswa memberikan formulir dan persyaratan kepada petugas kemudian petugas memasukkan data di buku besar (pembukuan). Jika digambarkan dengan use case diagram, maka sistem yang berjalan sebagai berikut

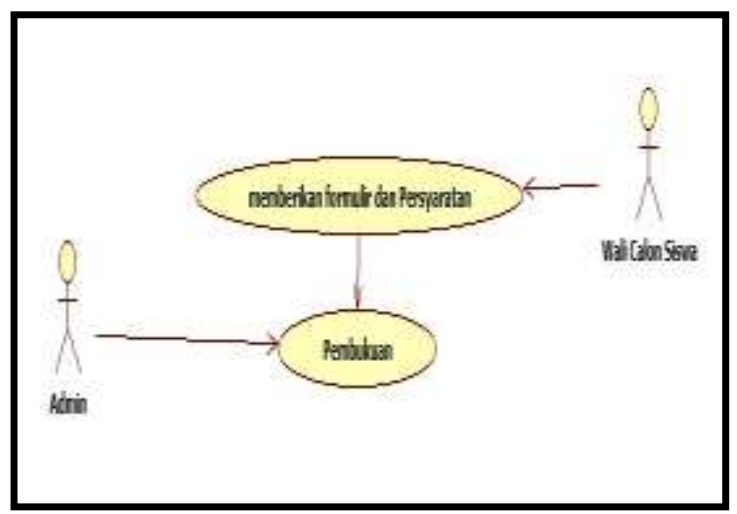

Gambar2. Sistem yang Berjalan

\subsubsection{Sistem yang Diusulkan}

Sistem yang akan diusulkan pada SD Methodist-5 Pagar Alam dengan menggunakan perangkat lunak bantu penerimaan siswa baru. Dimana sistem yang akan diusulkan ini telah terkomputerisasi yaitu wali calon siswa 
memberikan formulir dan persyaratan kepada petugas kemudian data tersebut di input pada perangkat lunak penerimaan siswa baru sehingga tidak menggunakan buku besar kembali untuk pendataannya. Jika digambarkan use case diagram, maka sistem

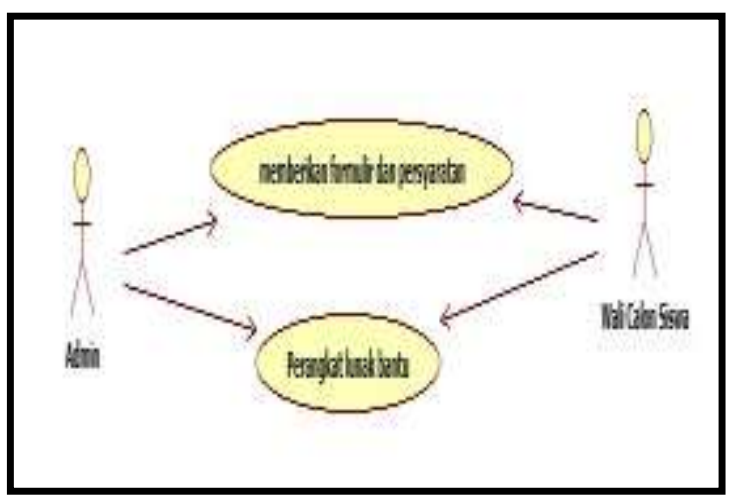

yang akan diusulkan sebagai berikut :

Gambar 3. Sistem yang diusulkan

\subsubsection{Use Case Diagram}

Use Case ditujukan untuk mempresentasikan sebuah interaksi antara aktor dengan sistem. Yang ditekankan pada Use Case ini ialah "apa" yang diperbuat sistem dan buka "bagaimana". Use case diagram petugas diharuskan melakukan Login dan dihadapkan oleh beberapa menu pilihan seperti mengelola admin, mengelola formulir dan mengelola laporan.

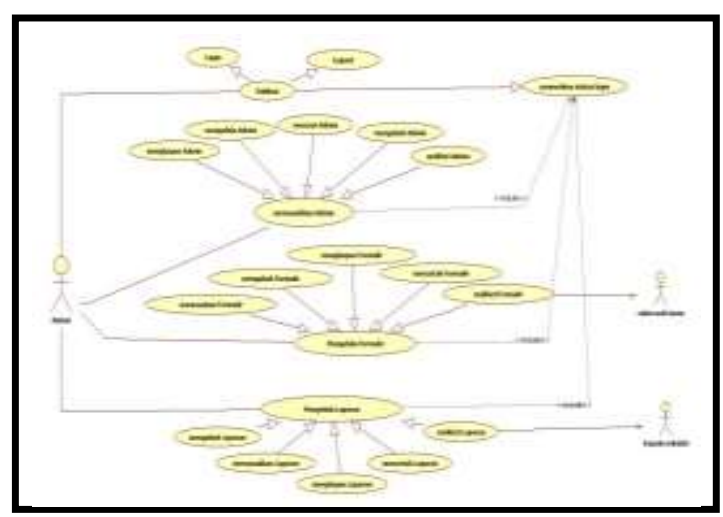

Gambar 4. Use Case Diagram

\subsubsection{Activity Diagram}

Rangkaian activity diagram bertujuan untuk mendeskripsikan aktivitas yang dibentuk dalam suatu operasi sehingga dapat berfungsi untuk aktivitas lainnya seperti pada interaksi use case. Penulis melakukan pengembangan aktivitas ialah sebagai berikut:

\section{Activity Diagram Petugas}

Pada activity diagrampetugas, penulis menggambarkan kegiatan petugas untuk mendeskripsikan aktivitas interaksinya dengan sistem. Petugas login terlebih dahulu untuk dapat masuk ke halaman petugas, jika username dan password benar maka akan tampil menu.Untuk lebih jelasnya, perhatikan gambar di bawah

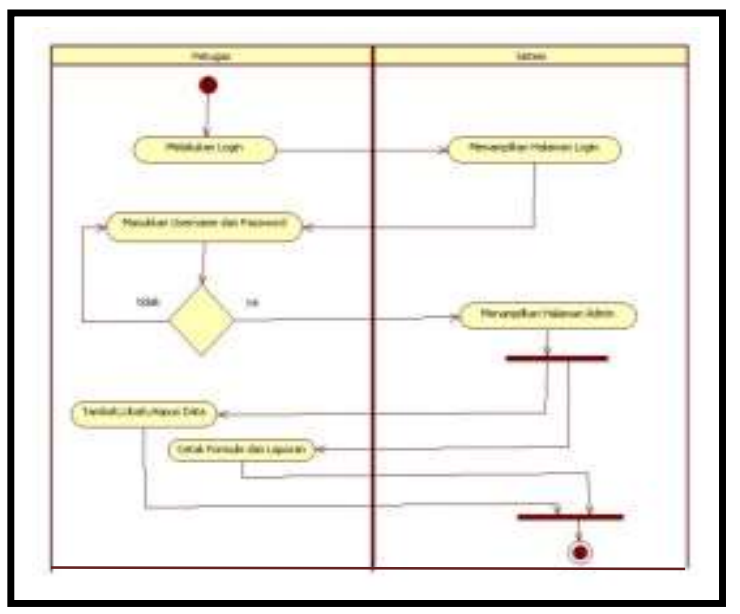

Gambar 5.Activity Diagram

\subsubsection{Sequence Diagram}

Untuk menggambar sequance diagram maka harus diketahui objek-objek yang terlibat dalam sebuah use case beserta metode-metode yang dimiliki kelas. Membuat sequance diagram juga dibutuhkan untuk melihat skenario yang ada pada use case. Penulis melakukan pengembangan aktivitas ialah sebagai berikut: 


\section{Sequance Diagram Petugas}

Sequance diagram

petugas menggambarkan interaksi antara petugaske dalam sistem dimana petugas dapat melakukan login ke dalam sistem dan melakukan cek validasi, tambah data, ubah data, hapus data dan melihat data. Kemudian sistem basis data akan menyimpan data yang baru ke dalam sistem. Untuk lebih jelasnya, perhatikan sequance diagram petugas di bawah ini:

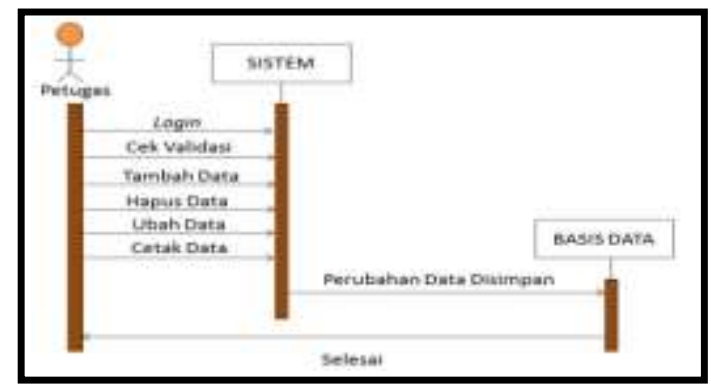

Gambar 6.Sequance Diagram

\subsubsection{Class Diagram}

Class diagram yaitu menggambarkan struktur sistem dari segi pendefinisian kelaskelas yang akan dibuat untuk membangun sistem. Class diagram memperhatikan aturanaturan dan tanggung jawab entitas yang menentukan perilaku sistem selama tahap desain. Untuk lebih jelasnya, perhatikan class diagram di bawah ini:

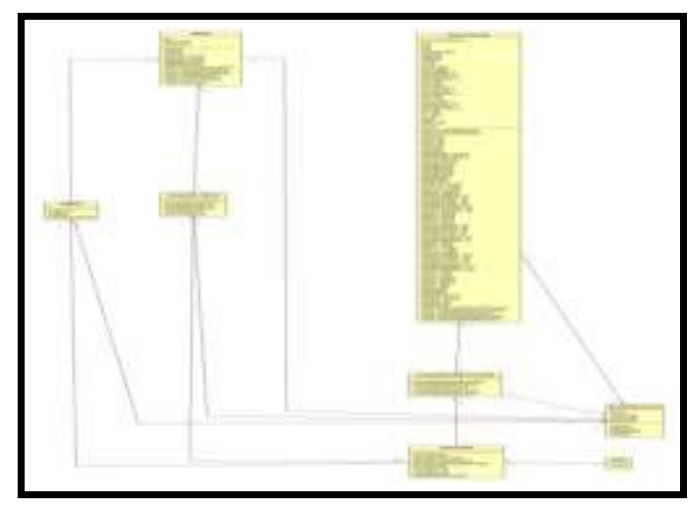

Gambar 7. Class Diagram

\subsection{Struktur Tabel}

Menurut (Rosa A.S, 2014, p. menjelaskan bahwa sistem basis data adalah sistem terkomputerisasi yang tujuan utamanya adalah memelihara data yang sudah diolah atau informasi dan membuat informasi tersedia saat dibutuhkan. Data dalam database biasanya saling terelasional antara satu dengan lainnya.

\subsubsection{Tabel Admin}

Tabel admin digunakan pada saat membuat database, dimana tabel ini memiliki fungsi sebagai acuan yang menjelaskan tentang field dan tipe data yang terdapat pada tabel admin.Dimana pada database ini terdiri dari beberapa field yaitu username dan password.

Tabel 1. Tabel Admin

\begin{tabular}{ccccc}
\hline $\begin{array}{l}\text { N } \\
\text { o. }\end{array}$ & Nama & Type & $\begin{array}{l}\text { Si } \\
\text { ze }\end{array}$ & Ket \\
\hline 1. & id* $^{*}$ & Int & 2 & Id \\
\hline 2. & Username & Varchar & 15 & Username \\
\hline 3. & Password & Varchar & 15 & Password
\end{tabular}

\section{*Primary Key}

\subsubsection{Tabel Formulir}

Tabel data formulir digunakan untuk memasukkan data pendaftaran seperti no_pendaftaran, nm, j_k, tempat_lahir, tgl_lahir, agama, alamat, no_hp, anak, nm_ayah, nm_ibu, pekerjaan_a,Pekerjaan_i, nm_wali, pekerjaan_w, fc_akte, fc_kk, map, pas_foto, biaya, ket dan tgl_input.

Tabel 2. Tabel Formulir

\begin{tabular}{lllll}
\hline $\begin{array}{c}\text { N } \\
\text { o. }\end{array}$ & Nama & Type & $\begin{array}{l}\text { Si } \\
z e\end{array}$ & \multicolumn{1}{c}{ Ket } \\
\hline 1. & $\begin{array}{l}\text { no_pendaft } \\
\text { aran* }\end{array}$ & Int & 4 & $\begin{array}{l}\text { No } \\
\text { Pendaftara } \\
\text { n }\end{array}$
\end{tabular}




\begin{tabular}{|c|c|c|c|c|}
\hline $\begin{array}{l}\mathbf{N} \\
\text { o. }\end{array}$ & Nama & Type & $\begin{array}{l}\text { Si } \\
z e\end{array}$ & Ket \\
\hline 2. & $\mathrm{Nm}$ & Varchar & 50 & Nama \\
\hline 3. & j_k & Varchar & 10 & $\begin{array}{l}\text { Jenis } \\
\text { Kelamin }\end{array}$ \\
\hline 4. & $\begin{array}{l}\text { tempat_lahi } \\
\mathrm{r}\end{array}$ & Varchar & 30 & $\begin{array}{l}\text { Tempat } \\
\text { lahir }\end{array}$ \\
\hline 5. & tgl_lahir & Varchar & 30 & $\begin{array}{l}\text { Tanggal } \\
\text { lahir }\end{array}$ \\
\hline 6. & Agama & Varchar & 20 & Agama \\
\hline 7. & Alamat & Text & & Alamat \\
\hline 8. & no_hp & Varchar & 12 & Telpon \\
\hline 9 & Anak & Varchar & 3 & Anak \\
\hline 10 & nm_ayah & Varchar & 25 & Nama ayah \\
\hline 11 & nm_ibu & Varchar & 25 & Nama ibu \\
\hline 12 & pekerjaan_a & Varchar & 25 & Pekerjaan \\
\hline 13 & pekerjaan_i & Varchar & 25 & Pekerjaan \\
\hline 14 & nm_wali & Varchar & 50 & Nama Wali \\
\hline $\begin{array}{l}15 \\
.\end{array}$ & $\begin{array}{l}\text { pekerjaan_ } \\
\mathrm{W}\end{array}$ & Varchar & 25 & Pekerjaan \\
\hline 16 & fc_akte & Varchar & 20 & $\begin{array}{l}\text { Fotocopi } \\
\text { Akte }\end{array}$ \\
\hline $\begin{array}{l}17 \\
.\end{array}$ & fc_kk & Varchar & 20 & $\begin{array}{l}\text { Fotocopi } \\
\text { KK }\end{array}$ \\
\hline 18 & Map & Varchar & 20 & Map folio \\
\hline $\begin{array}{c}19 \\
.\end{array}$ & pas_foto & Varchar & 20 & $\begin{array}{l}\text { Pas Foto } \\
3 \times 4\end{array}$ \\
\hline 20 & Biaya & Varchar & 20 & $\begin{array}{l}\text { Biaya } \\
\text { Pendaftara } \\
\mathrm{n}\end{array}$ \\
\hline 21 & Ket & Varchar & 20 & $\begin{array}{l}\text { Keteranga } \\
\mathrm{n}\end{array}$ \\
\hline 22 & tgl_input & Varchar & 75 & Tanggal \\
\hline
\end{tabular}

*Primary Key

\subsection{Desain Storyboard}

\subsubsection{Desain Halaman Login}

Desain halaman login merupakan tampilan awal pada saat perangkat lunak penerimaan siswa baru dibuka. Desain halaman utama berisi username dan password .Desain dapat dilihat seperti gambar dibawah ini :

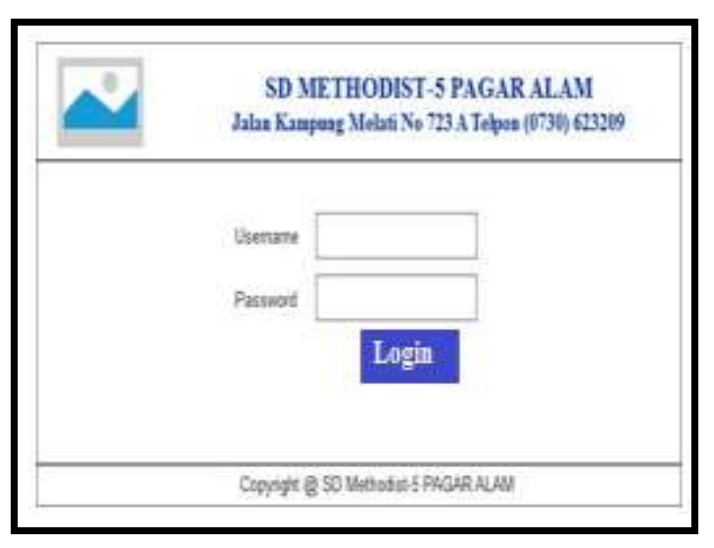

Gambar 8. Halaman Login

\subsubsection{Desain Halaman MenuHome}

Desain halaman home merupakan tampilan awal pada saat perangkat lunak penerimaan siswa baru masuk setelah login. Desain halaman home dapat dilihat seperti gambar dibawah ini :

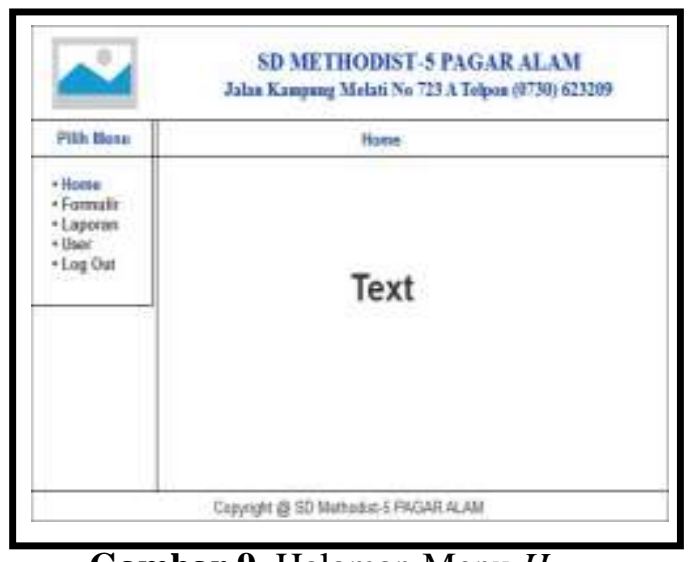

Gambar 9. Halaman Menu Home

\subsubsection{Desain Halaman Formulir}

Desain halamanformulir merupakan tampilan untuk menambah data calon siswa. Pada desain halaman formulir ini terdapat form akan disi yaitu nama, jenis kelamin, tempat 
tanggal lahir, agama, alamat, telpon, anak ke, nama ayah, nama ibu, pekerjaan ayah, pekerjaan ibu, nama wali, pkerjaan wali, fotocopy akte kelahiran, fotocopy kartu keluarga, map, pas foto dan biaya pendaftaran. Halaman formulir dapat dilihat seperti gambar dibawah ini :

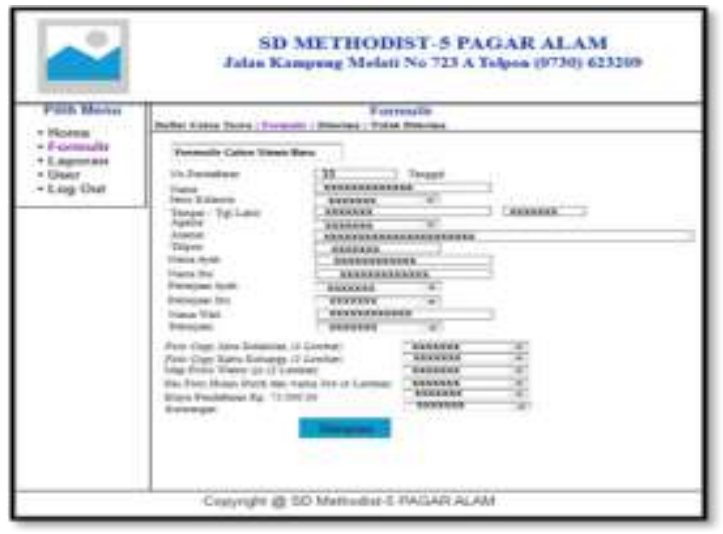

Gambar 10. HalamanFormulir

\subsubsection{Desain Halaman Cetak Formulir}

Desain halaman cetak formulimerupakan tampilan hasil dari input formulir sebelumnya. Halaman cetak formulir dapat dilihat seperti gambar dibawah ini :

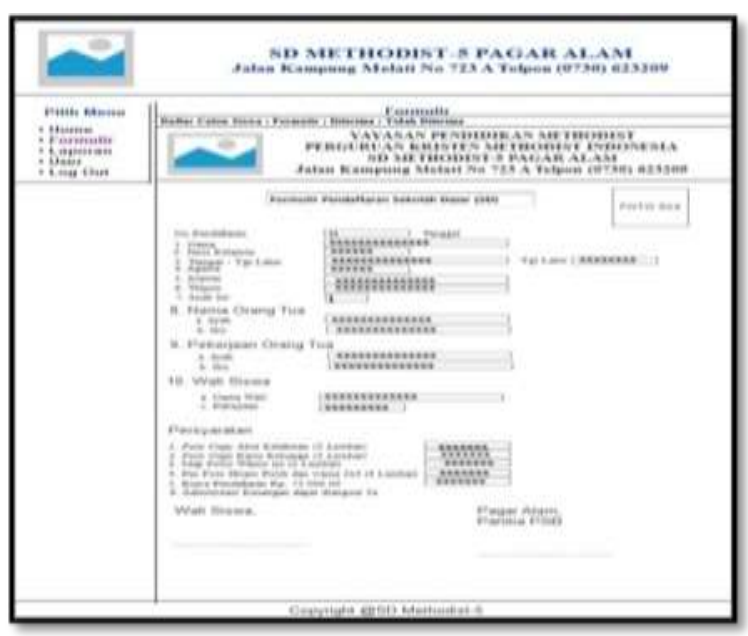

Gambar 11. Halaman Cetak Formulir

\subsubsection{Desain Halaman Menu Laporan}

Desain halaman menu laporan merupakan halaman ketiga dari menu utama.
Pada menu ini terdapat form data calon siswa, cetak laporan, non muslim, muslim, PNS dan non PNS. Halaman menu laporan dapat dilihat seperti gambar dibawah ini:

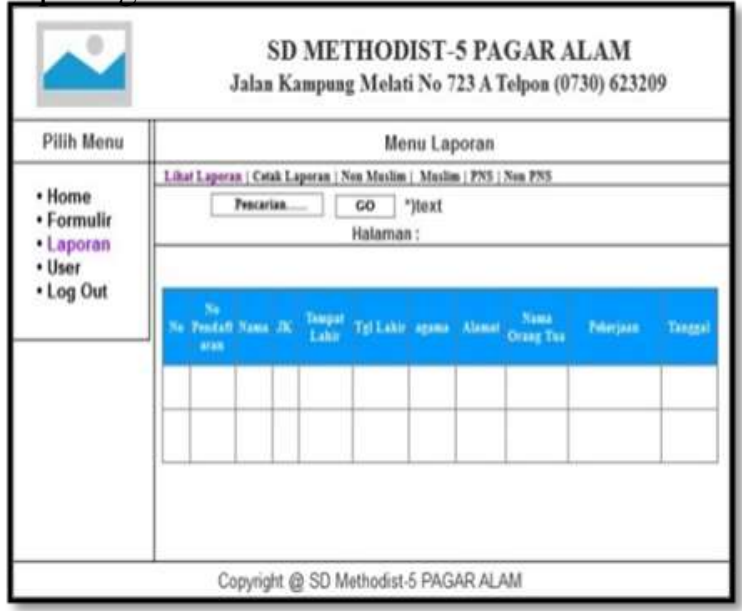

Gambar 12.Halaman Menu Laporan

\subsubsection{Desain Halaman Cetak Laporan}

Desain cetak laporan merupakan tampilan data laporan calon siswa baru yang akan dicetak. Terdapat tabel yang didalamnya terdiri dari no, no pendaftaran, nama, jenis kelamin, tempat lahir, tanggal lahir, agama, alamat, nama orang tua dan pekerjaan. Halaman cetak laporan dapat dilihat seperti gambar dibawah ini:

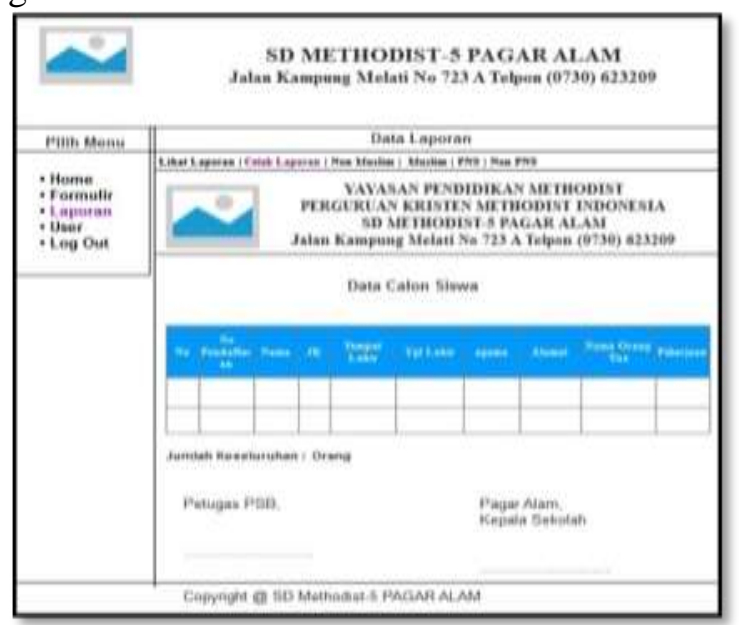

Gambar 13. Halaman Cetak Laporan

\subsubsection{Desain Halaman Menu User}

Desain menu user merupakan halaman keempat dari pilihan menu utama. Dimana dapat dilihat seperti gambar dibawah ini : 
Gambar 14. Halaman Menu User

\subsubsection{Desain Halaman MenuLogout}

Desain halaman menu logout merupakan tampilan untuk mengakhiri perangkat lunak bantu penerimaan siswa baru. Desain menu logout dapat dilihat seperti gambar dibawah ini:

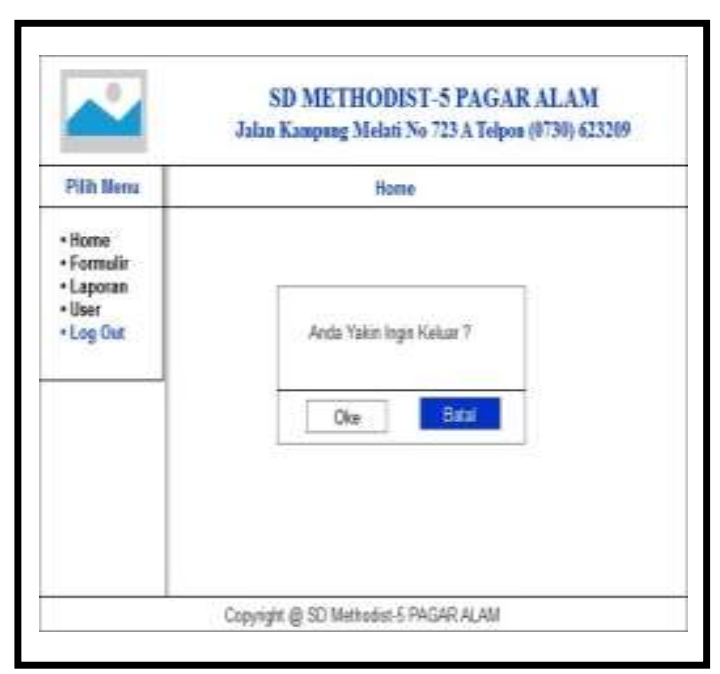

Gambar 15. Halaman Menu Logout

\section{HASIL DAN PEMBAHASAN}

\subsection{HASIL}

Pada bab ini peneliti membuat perangkat lunak bantu penerimaan siswa baru pada SD Methodist-5 Pagar Alam yang dapat membantu petugas penerimaan siswa baru dalam mengelola data calon siswa. Proses pelayanan dan pendataan pada penerimaan siswa baru yang berbasis komputerisasi dapat membantu pengolahan data dan pengarsipan data penerimaan calon siswa baru. Perangkat lunak bantu penerimaan siswa baru SD Methodist-5 Pagar Alam di buat untuk membantu dalam proses pendataan calon siswa baru sehingga pengolahan data akan menjadi lebih baik.

\subsection{PEMBAHASAN}

Batasan dari perangkat lunak bantu ini hanya dapat menginput formulir, mencetak formulir, menampilkan laporan daftar calon siswa, mengubah dan menghapus data. Perangkat lunak bantu penerimaan siswa baru SD Methodist-5 Pagar Alam memiliki beberapa menu pilihan diantaranya home, formulir, laporan, user dan logout.

\subsubsection{Desain Halaman Login}

Desain halaman utama merupakan tampilan awal pada saat perangkat lunak penerimaan siswa baru dibuka. Desain halaman utama berisi username dan password .Desain dapat dilihat seperti gambar dibawah ini :

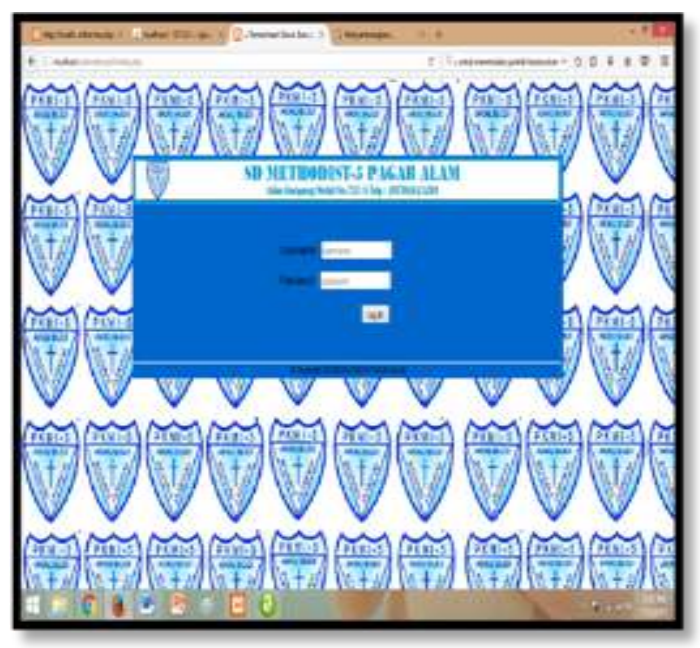




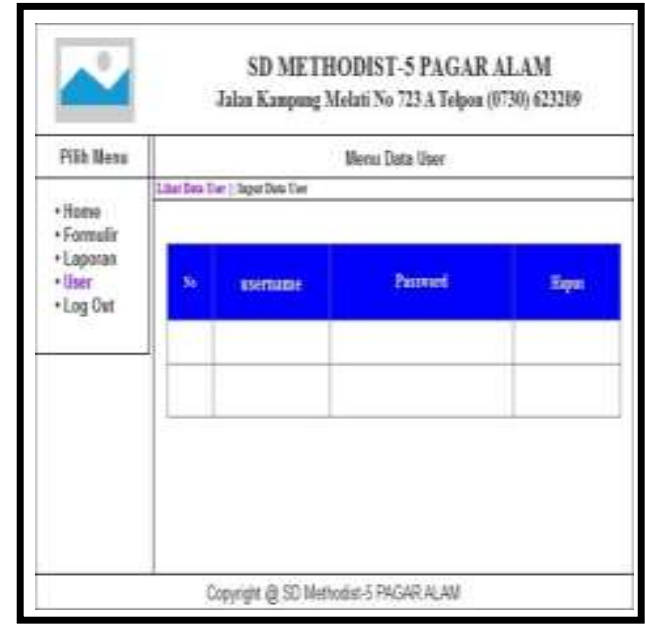

Gambar 16. Halaman Login

\subsubsection{Desain Halaman Menu Home}

Desain halaman home merupakan tampilan awal pada saat perangkat lunak penerimaan siswa baru masuk setelah login yang menampilkan halaman depan dari perangkat lunak bantu penerimaan siswa baru. Desain halaman home dapat dilihat seperti gambar dibawah ini :

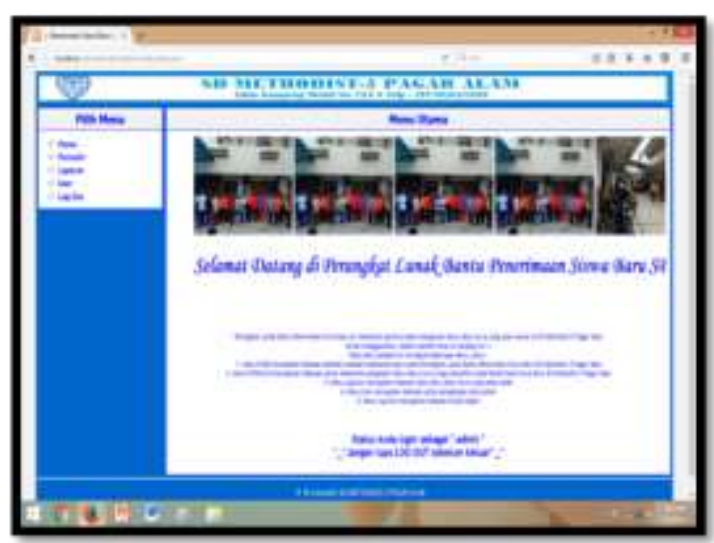

Gambar 17. Halaman Menu Home

\subsubsection{Desain Halaman Formulir}

Desain halamanformulir merupakan tampilan untuk menambah data calon siswa. Pada desain halaman formulir ini terdapat form akan disi yaitu nama, jenis kelamin, tempat tanggal lahir, agama, alamat, telpon, anak ke, nama ayah, nama ibu, pekerjaan ayah, pekerjaan ibu, nama wali, pkerjaan wali, foto copy akte kelahiran, foto copy kartu keluarga, map warna biru, pas foto hitam putih dan berwarna $3 \times 4$ dan biaya pendaftaran $\mathrm{Rp}$ 75.000,-. Halaman formulir dapat dilihat seperti gambar dibawah ini:

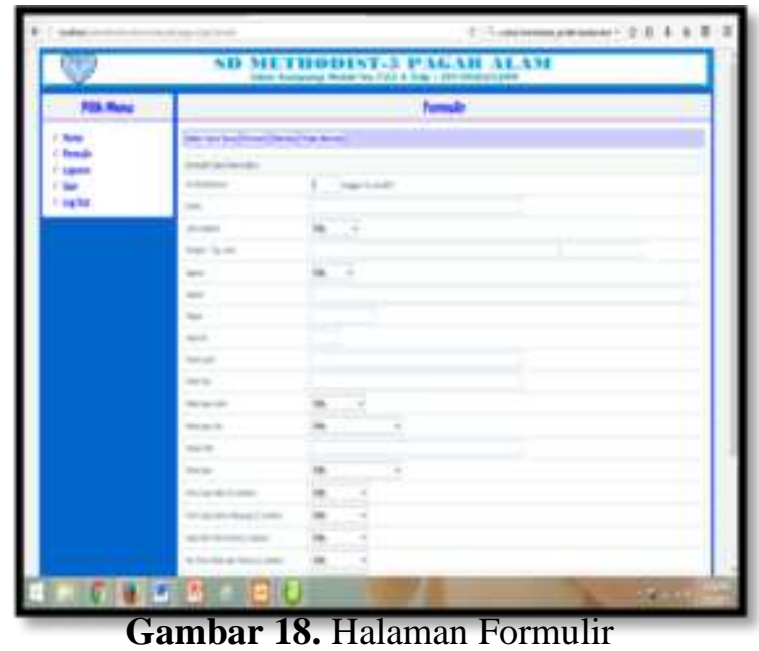

\subsubsection{Desain Halaman Cetak Formulir}

Desain halaman cetak formulir merupakan tampilan hasil dari input formulir sebelumnya. Hasil cetak formulir ini akan diberikan kepada wali calon siswa baru sebagai bukti bahwa telah mendaftar sebagai calon siswa baru pada SD Methodist-5 Pagar Alam. Halaman cetak formulir dapat dilihat seperti gambar dibawah ini:

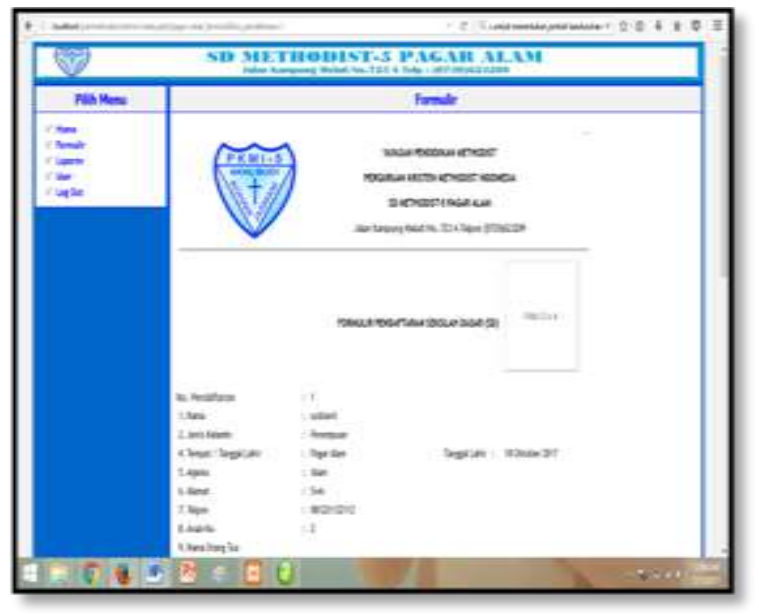

Gambar 19. Halaman Cetak Formulir 


\subsubsection{Desain Halaman Menu Laporan}

Desain halaman menu laporan merupakan halaman ketiga dari menu utama. Dimana terdapat form data calon siswa, cetak laporan, non muslim, muslim pns dan non pns.Dimana dapat dilihat seperti gambar dibawah ini:

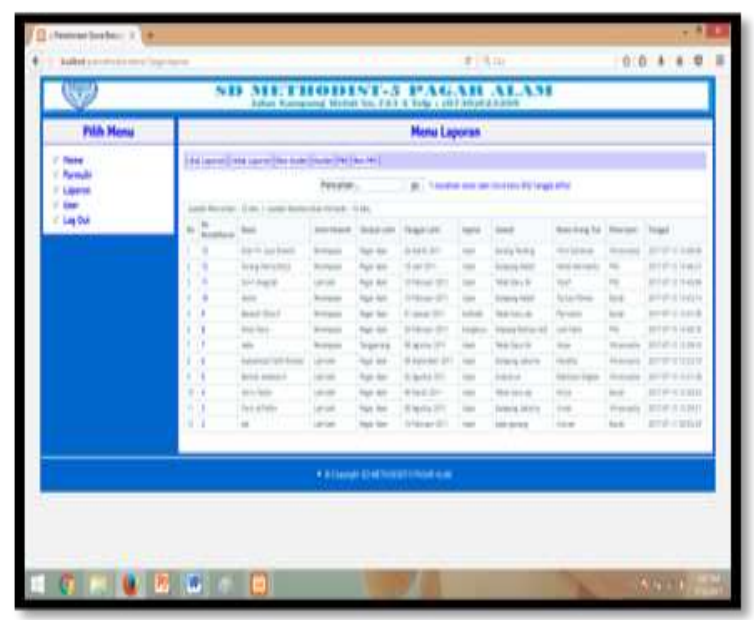

Gambar 20.Halaman Menu Laporan

\subsubsection{Desain Halaman Cetak Laporan}

Desain cetak laporan merupakan tampilan data laporan calon siswa baru yang akan dicetak. Halaman ini merupakan laporan kesuluruhan calon siswa yang mendaftar, seperti gambar dibawah ini:

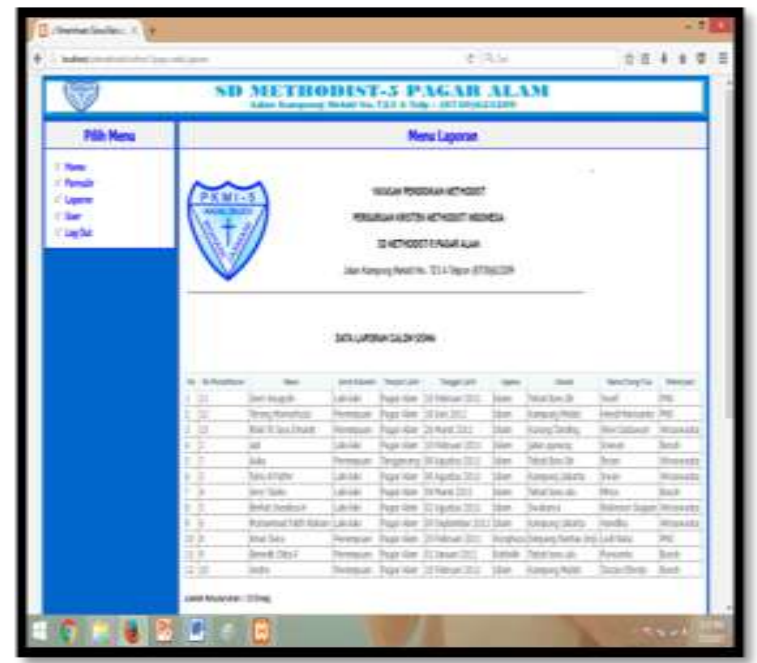

Gambar 21. Halaman Cetak Laporan

\subsubsection{Desain Halaman Menu User}

Desain menu user adalah tampilan menu user yang meliputi data user dan input data user. Halaman menu user dapat dilihat seperti gambar dibawah ini:

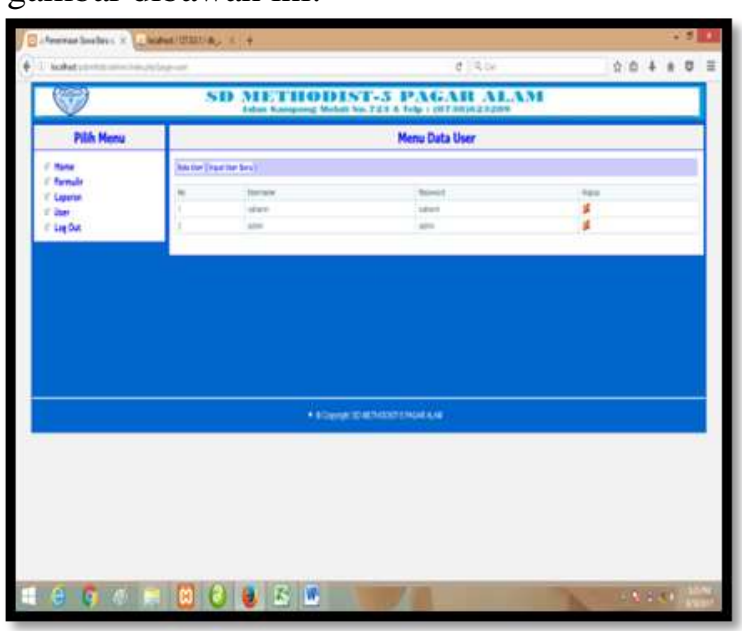

Gambar 22. Halaman Menu User

\subsubsection{Desain Halaman Menu Logout}

Desain halaman menu logout merupakan tampilan untuk mengakhiri perangkat lunak bantu penerimaan siswa baru. Halaman menu logout dapat dilihat seperti gambar dibawah ini:

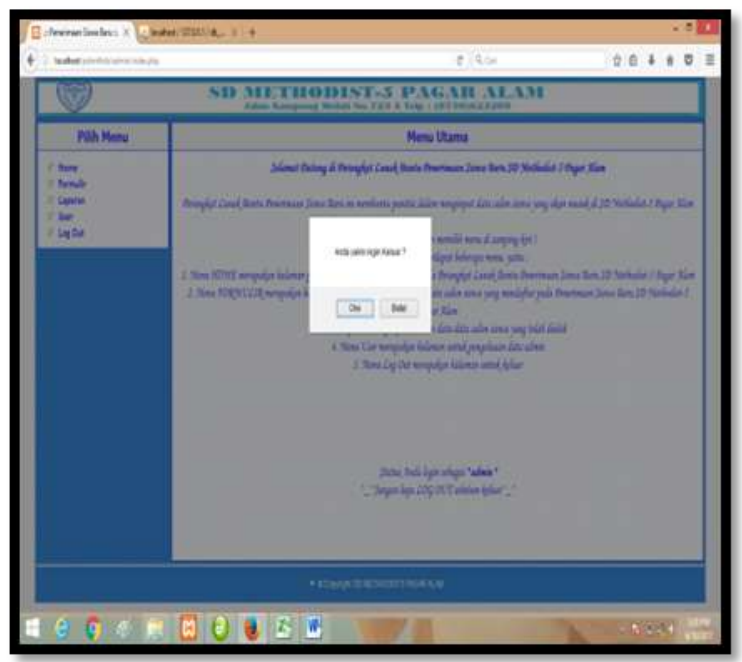

Gambar 23. Halaman Menu Logout

\section{SIMPULAN}

Dalam penelitian ini telah diuraikan bagaimana membuat perangkat lunak bantu 
penerimaan siswa baru yang bertujuan untuk membantu petugas penerimaan siswa baru dalam pendataan calon siswa baru pada SD Methodist-5 Pagar Alam. Perangkat lunak bantu ini membantu petugas penerimaan siswa baru yang sebelumnya mencatat data menggunakan buku besar menjadi terkomputerisasi. Perangkat lunak bantu ini hanya dapat menginput data formulir, menampilkan data formulir dan menampilkan data laporan pendaftaran calon siswa baru sehingga data menjadi lebih mudah diproses, cepat dan akurat.

\section{DAFTAR RUJUKAN}

Abdul, K. (2002). Pengenalan Sistem Informasi. In K. Adbul, Pengenalan sistem Informasi (p. 254). Yogyakarta: ANDI Yogyakarta.

Arief, M. R. (2011). Pemrograman Web Dinamis Menggunakan PHP dan MySQL. In M. R. Arief, Pemrograman Web Dinamis Menggunakan PHP dan MySQL (p. 19). Yogyakarta: ANDI Yogyakarta.

dkk, N. H. (2013). Aplikasi Penerimaan Siswa Baru Berbasis WEB (SMK N 3 Yogyakarta). Aplikasi Penerimaan Siswa Baru Berbasis WEB (SMK N 3 Yogyakarta), 1-8. Telematika Vol.10, No.1, Juli 2013, ISSN 1829-667 .

M.Salahuddin, R. A. (2014). rekayasa perangkat lunak tersruktur dan berorientasi objek. In R. A. M.Salahuddin, rekayasa perangkat lunak tersruktur dan berorientasi objek (p. 155). Bandung: INFORMATIKA.

Santoso. (2015). Sistem Informasi Pendaftaran Siswa Baru Pada SMK Di Ponorogo Tulakan. Sistem Informasi Pendaftaran Siswa Baru Pada SMK Di Ponorogo Tulakan, 1-7. Journal Speed - Swntra Penelitian Engineering dan Edukasi Volume \& No 1 - 2015. ISSN : 1979-9330.

T, A. H. (2008). adobe dreamweaver cs3 dan php. In A. H. T, adobe dreamweaver cs3 dan php (p. 3). Yogyakarta: Andy Yogyakarta.

Wahyu Hidayat, d. (2013). Pembaangunan sistem informasi pendaftaran siswa baru SMP Negeri 2 Sudimoro Pacitan. Pembaangunan sistem informasi pendaftaran siswa baru SMP Negeri 2 Sudimoro Pacitan, 1-6. IJNS - Indonesia Jounal on Network and Security - ISSN : 2302-5700.

Warist Amru Khoiruddin, d. (2011). Apliaksi Penerimaan Siswa Baru untuk Menunjang Sekolah RSBI menjadi SBI berbasis WEB . Apliaksi Penerimaan Siswa Baru untuk Menunjang Sekolah RSBI menjadi SBI berbasis WEB , 1-6.

Ian Sommerville. (2003). Software Engineering Rekayasa Perangkat Lunak. 56 